\title{
One-Pot Wittig Reactions in Water and in the Presence of a Surfactant
}

\author{
Fulvia Orsini,* Guido Sello, Tiziano Fumagalli \\ Dipartimento di Chimica Organica ed Industriale, via Venezian 21, 20133 Milano, Italy \\ E-mail: fulvia.orsini@unimi.it \\ Received 15 March 2006
}

\begin{abstract}
Unsaturated esters were synthesized in open atmosphere via mild and efficient one-pot Wittig reactions performed in both water and sodium dodecyl sulfate (SDS)-water solution.
\end{abstract}

Key words: alkenes, esters, Wittig reaction, micelles

For a long time, volatile organic compounds (VOC) have been considered the best solvents for carbon-carbon bond formation, in contrast with the several enzymatic processes that occur in aqueous environment. Nevertheless, in most recent decades, there has been an increasing interest in water as solvent for organic reactions, with several advantages with respect to the use of VOC in terms of cost, simplification of protection-deprotection processes, safety and environmental concern. ${ }^{1}$

The Wittig reaction, one of the most important methods to synthesize carbon-carbon double bond, is traditionally carried out in an homogeneous, anhydrous and aprotic solvent using an organometallic base to generate a stabilized or semistabilized phosphonium ylide. ${ }^{2}$

Water was used in few cases as the solvent: water-soluble formaldehyde, ${ }^{3}$ water-soluble semistabilized phosphonium ylides, ${ }^{4}$ water-soluble PEG-supported salts were used. ${ }^{5}$ The scope of aldehydes substrates was, however, limited by their solubility. In addition, reactions between trialkylphosphonoacetates and 2-oxoalkanphosphonates were reported. They were performed in concentrated basic solution in which both the phosphonium salts and the ylides were decomposed. ${ }^{6}$ Recently, reactions involving preformed stabilized ylides and performed in water were reported, but high temperature $\left(90^{\circ} \mathrm{C}\right)$ and $\mathrm{LiCl}$ as additive were generally required., ${ }^{7,8}$

An appealing possible way to solve the problem of waterinsoluble or scarcely soluble substrates could be the use of micelles. Reactions in micellar systems have received a growing attention in the last decades, so many reactions were reported to mimic biochemical processes: esters hydrolysis, hydrocarbons oxidations as well as carbon-carbon coupling reactions. ${ }^{9}$

In this paper are reported the results so far obtained in a study concerning one-pot Wittig reactions between in situ prepared ylides and aldehydes. They are carried out without using the inert atmosphere in both water and sodium

SYNLETT 2006, No. 11, pp 1717-1718

Advanced online publication: 04.07.2006

DOI: 10.1055/s-2006-947323; Art ID: G09306ST

(c) Georg Thieme Verlag Stuttgart · New York dodecyl sulfate (SDS)-water solution. Judging from the critical micelles concentration, micelles would be formed in the latter system.

The one-pot procedure advantages (no work-up, no need to isolate the intermediates, saving of solvent and time) are obvious. A micellar system was pursued in order to create a micro hydrofobic domain in water to favor more lipophilic substrates and to test the possibility of modifying the conformational equilibrium, which consequently influences the stereoisomeric ratio.

The attention was focused on the stabilized ylides to obtain $\alpha, \beta$-unsaturated esters. They are precursors either of natural and unnatural hydroxy or amino acids and other bioactive compounds. To this purpose ethyl $\alpha$-bromoacetate and tri- $n$-butyl phosphine were added to an aqueous solution of SDS to give the phosphonium dodecylsulfate salt (that was also isolated) ${ }^{10}$ followed by addition of the aldehyde and triethylamine. ${ }^{11}$

Yields are almost the same, in water and in the presence of sodium dodecylsulfate, for the least lipophilic 4-nitro benzaldehyde (Table 1, entry 1). In the other examples the

Table 1 Wittig-Type Reactions Performed in Water and in Micellar System

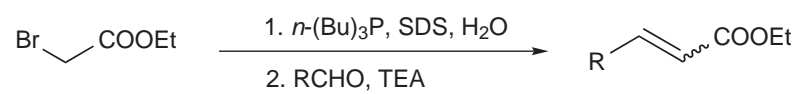

\begin{tabular}{clllll}
\hline Entry & Electrophile & Medium & Yield (\%) & $Z$ & $E$ \\
\hline 1 & $4-\mathrm{NO}_{2} \mathrm{C}_{6} \mathrm{H}_{4} \mathrm{CHO}$ & Micelles & 87 & 10 & 90 \\
2 & $4-\mathrm{NO}_{2} \mathrm{C}_{6} \mathrm{H}_{4} \mathrm{CHO}$ & $\mathrm{H}_{2} \mathrm{O}$ & $88^{7,12}$ & 13 & 87 \\
3 & 2 -Furfural & Micelles & $85(+4)$ & 11 & 89 \\
4 & 2-Furfural & $\mathrm{H}_{2} \mathrm{O}$ & $82^{7}$ & 20 & 80 \\
5 & $4-\mathrm{MeOC}_{6} \mathrm{H}_{4} \mathrm{CHO}$ & Micelles & $76(+12)$ & 2 & 98 \\
6 & $4-\mathrm{MeOC}_{6} \mathrm{H}_{4} \mathrm{CHO}$ & $\mathrm{H}_{2} \mathrm{O}$ & $68^{7,8}$ & 4 & 96 \\
7 & $\mathrm{PhCH}_{2} \mathrm{CH}_{2} \mathrm{CHO}$ & Micelles & $88(+11)$ & 25 & 75 \\
8 & $\mathrm{PhCH}_{2} \mathrm{CH}_{2} \mathrm{CHO}$ & $\mathrm{H}_{2} \mathrm{O}$ & $79^{13}$ & 19 & 81 \\
9 & $(E)-\mathrm{PhCH}^{2} \mathrm{CHCHO}$ & Micelles & $90(+10)$ & 14 & 86 \\
10 & $(E)-\mathrm{PhCH}_{2} \mathrm{CHCHO}$ & $\mathrm{H}_{2} \mathrm{O}$ & $82^{14}$ & 11 & 89 \\
11 & $\left.n-\mathrm{Me}_{(\mathrm{CH}}\right)_{6} \mathrm{CHO}$ & Micelles & $91(+26)$ & 24 & 76 \\
12 & $n-\mathrm{Me}_{2}\left(\mathrm{CH}_{2}\right)_{6} \mathrm{CHO}$ & $\mathrm{H}_{2} \mathrm{O}$ & $72^{7}$ & 18 & 82 \\
\hline
\end{tabular}

a Increment (\%) respect to $\mathrm{H}_{2} \mathrm{O}$. 
yields increase in the latter medium: the maximum gap between the two media was observed with the most liphophilic aldehyde ( $n$-octanal). In all cases the $E$ isomer was the major product; however, the $E / Z$ ratio depended on both the medium and the substrate.

Concluding, we have developed a mild and efficient 'onepot' Wittig protocol, which works well in water at room temperature, and even better in the presence of sodium dodecyl sulfate, especially when the lipophilicity of the carbonyl compound increases.

To widen the scope of this new protocol, work is in progress to test semistabilized ylides, other surfactants (cationic, non-ionic) and complex substrates, potentially precursors of bioactive compounds.

\section{Typical Procedure for Reactions in Water}

In open atmosphere, tri- $n$-butylphosphine $(247 \mu \mathrm{L})$, was added at r.t. to a stirred solution of ethyl $\alpha$-bromo acetate $(1.0 \mathrm{mmol})$ in deionized $\mathrm{H}_{2} \mathrm{O}(1.0 \mathrm{~mL})$. After $5 \mathrm{~min}$ aldehyde $(1.1 \mathrm{mmol})$ was added, followed, after $10 \mathrm{~min}$, by addition of $\mathrm{Et}_{3} \mathrm{~N}(140 \mu \mathrm{L}, 1 \mathrm{mmol})$. The reaction was monitored by TLC (Glass supported silica gel plates; eluent: EtOAc-PE, 5:95). After about $1.5 \mathrm{~h}$, the aqueous layer was extracted with EtOAc $(3 \times 15 \mathrm{~mL})$. The combined organic extracts were dried $\left(\mathrm{Na}_{2} \mathrm{SO}_{4}\right)$ and the solvent removed under reduced pressure. The crude material was purified by flash chromatography ${ }^{15}$ [silica gel 60, 230-400 mesh; sample loading (mg)/column diameter (mm): 100/10; eluent: EtOAc-PE, 5:95] to remove unreacted aldehyde, phosphinoxide and afford the desired product.

\section{Typical Procedure for Reactions in Micellar System}

Under stirring in open atmosphere, ethyl $\alpha$-bromoacetate (1.0 mmol) was added to a solution of SDS $(0.10 \mathrm{~g})$ in $\mathrm{H}_{2} \mathrm{O}(1.0 \mathrm{~mL})$, followed by the addition of tri- $n$-butylphosphine (1.0 mmol). After 5 min aldehyde $\left(1.1 \mathrm{mmol}\right.$ ) was added, followed by addition of $\mathrm{Et}_{3} \mathrm{~N}$ $(1.0 \mathrm{mmol})$. Vigorous stirring was continued for about $2 \mathrm{~h}$, while the reaction was monitored by TLC (silica gel; EtOAc-PE, 5:95). Work-up was performed as described above.

\section{Acknowledgment}

Universita' degli Studi di Milano and MIUR (Ministero dell' Istruzione, dell' Universita' e della Ricerca) are acknowledged for financial support (FIRB: Project code n. RBAU017KFW - FIRST).

\section{References and Notes}

(1) (a) Sinou, D. Adv. Synth. Catal. 2002, 344, 221. (b) Lindstroem, U. M. Chem. Rev. 2002, 102, 2751.

(2) Maryanoff, B. E.; Reitz, A. B. Chem. Rev. 1989, 89, 863.

(3) Broos, R.; Anteunis, M. Synth. Commun. 1976, 6, 53.

(4) (a) Russel, M. G.; Warren, S. Tetrahedron Lett. 1998, 39, 7995. (b) Russel, M. G.; Warren, S. J. Chem. Soc., Perkin Trans. 1 2000, 505.

(5) Sieber, F.; Wentworth, P. Jr.; Toker, J. D.; Wentworth, A. D.; Metz, W. A.; Reed, N. N.; Janda, K. D. J. Org. Chem. 1999, 64, 5188.

(6) Villieras, J.; Rambaud, M.; Graff, M. Tetrahedron Lett. 1985, 26, 53.

(7) Wu, J.; Zhang, D.; Wie, S. Synth. Commun. 2005, 35, 1213.

(8) Dambacher, J.; Zhao, W.; El-Batta, A.; Anness, R.; Jiang, C.; Bergdahl, M. Tetrahedron Lett. 2005, 46, 4473.

(9) Dwars, T.; Paetzold, E.; Oehme, G. Angew. Chem. Int. Ed. 2005, 44, 7174 .

(10) Phosphonium dodecylsulfate was isolated from a blank reaction performed as reported below in the absence of the base and of the electrophile: ethyl $\alpha$-bromo acetate $(0.5$ $\mathrm{mmol}$ ) was added, under stirring, to a solution of SDS (0.05 g) in $\mathrm{H}_{2} \mathrm{O}(0.5 \mathrm{~mL})$, followed by the addition of tri- $n$ butylphosphine $(0.5 \mathrm{mmol})$. The reaction mixture was poured in EtOAc $(10 \mathrm{~mL}) ; \mathrm{Na}_{2} \mathrm{SO}_{4}$ was added under stirring to remove $\mathrm{H}_{2} \mathrm{O}$, filtered and washed with EtOAc $(3 \times 5 \mathrm{~mL})$. The organic solvent was removed under reduced pressure. The residue was washed with $n$-hexane, dried, and dissolved in $\mathrm{CDCl}_{3}:{ }^{1} \mathrm{H} \mathrm{NMR}\left(\mathrm{CDCl}_{3}\right): \delta=0.86(3 \mathrm{H}, \mathrm{t}, J=7.0 \mathrm{~Hz})$, $0.96(9 \mathrm{H}, \mathrm{t}, J=6.8 \mathrm{~Hz}), 1.20-1.23(16 \mathrm{H}, \mathrm{m}), 1.31(3 \mathrm{H}, \mathrm{t}$, $J=6.8 \mathrm{~Hz}), 1.30-1.45(2 \mathrm{H}, \mathrm{m}), 1.45-1.55(12 \mathrm{H}, \mathrm{m}), 1.55-$ $1.70(2 \mathrm{H}, \mathrm{m}), 2.40-2.50(6 \mathrm{H}, \mathrm{m}), 3.79(2 \mathrm{H}, \mathrm{d}, J=13.2 \mathrm{~Hz})$, $4.01(2 \mathrm{H}, \mathrm{t}, J=7.5 \mathrm{~Hz}), 4.20(2 \mathrm{H}, \mathrm{q}, J=6.8 \mathrm{~Hz})$.

(11) All products were isolated by flash chromatography. Their purity, structure and stereoisomeric ratios (when $E / Z$ mixtures were obtained) were determined by ${ }^{1} \mathrm{H}$ NMR analysis, in comparison with the literature data.

(12) Zhao, H.; Cai, M. Z.; Peng, C. Y. Synth. Commun. 2002, 32 , 3419.

(13) Barrett, A. G. M.; Cramp, S. M.; Roberts, R. S.; Zecri, F. J. Org. Lett. 1999, 1, 579.

(14) (a) Concellon, J. M.; Concellon, C.; Mejica, C. J. Org. Chem. 2005, 70, 6111. (b) Suri, C. S.; Marcischak, C. J. Synth. Commun. 2005, 35, 379.

(15) Still, W. C.; Kahn, M.; Mitra, A. J. Org. Chem. 1978, 43, 2923. 